THE NERVOUS SYSTEM: STRUCTURE AND FUNCTION IN DISEASE. By D. M. Robertson and H. B. Dinsdale. (Pp. 204 ; illustrated; £6.25.) Churchill Livingstone: Edinburgh. 1972.

Though to many medical students modern neurophysiology may seem more dramatic, it is still neuroanatomy and neuropathology that provide the soundest basis for a wide understanding of neurological diseases. Now that courses at most medical schools are being reorganized so that clinical medicine and pathology are studied concurrently, a book of this kind linking neuropathology and neurology is welcome. This emphasis, however, precludes any extensive or systematic discussion about treatment except where, for example, in Parkinsonism this is a reflection of the pathological disturbance of the disease process. This raises the question of how many textbooks of neurology a student will read because this book, excellent though it is in its way, could not supplant a general textbook of clinical neurology. Perhaps we should be thankful that there are as many kinds of medical students as there are of doctors. I am sure many students will find this book gives an interesting balance with the tantalizing bait of some up-to-date information on recent neurochemical advances. My only complaint is of the price of $£ 6.25$, for which I think we ought at least to expect some colour photographs which would add to the attraction of the neuropathology.

\section{ROGER BANNISTER}

HYDROCEPHALUS AND THE CEREBROSPINAL FLUID By

Thomas H. Milhorat. (Pp. 237; illustrated; £8.50.) Churchill Livingstone: Edinburgh. 1972.

This monograph brings together information about hydrocephalus in a form intended primarily for clinicians. The chapters cover the causes, effects, diagnosis and management of hydrocephalus, and they are excellent reviews of the subject. The illustrations are of good quality, and the book is well arranged and easy to read. The text is supported by extensive bibliographies to each chapter, there being over 700 references quoted. The references are given in the text by name and year; this is unusual in present-day medical books from the United States, and many will consider this arrangement to be the most helpful in a monograph, although not suitable in undergraduate or postgraduate texts.

The book has been written by a distinguished surgeon who has made original contributions to the operative management of hydrocephalus, and the surgical features of the subject are therefore well covered. Unfortunately, however, the text is sometimes a little thin in aspects which might be of more interest to physicians. For example, the composition of cerebrospinal fluid is only briefly discussed in just over a page, which seems inadequate in a book which includes cerebrospinal fluid in its title. Another example is the very limited discussion of the differential diagnosis of dementia. Although this book gives an excellent review of all diagnostic techniques which are currently in general use, it fails to mention the exciting recent development of tomography by means of computerized transverse axial scanning.

Nevertheless, this book is strongly recommended for reference in its field. The author has produced a text which is of value for reading in depth, and its arrangement of headings, each section being followed by a clearly written summary, also makes it useful for quick referral.

RALPH H. JOHNSON

PRINCIPLES OF CHILD PSYCHOTHERAPY By J. D. Clarke. (Pp. 226; \$10.75.) Thomas: Springfield, Ill. 1972.

This is an ambitiously conceived book, written from Professor Carek's wide experience in the U.S.A., yet it is relevant to British N.H.S. hospital-based child psychiatry. It is practically based, but the author is able to avoid making too expansive use of case material to illustrate his principles. These 'principles' are derived from individual therapy which has as it's aim ego strengthening and insight and, although a wide bibliography is referred to, the psychotherapy seems broadly based on Anna Freud's work. The difficult task of organizing the complex subject has been thoughtfully approached. The style is ponderous and lacks the eloquence of other authors in that field, thus conveying a deliberate avoidance of persuasiveness. There is a good deal of healthy questioning of widely held beliefs, reflecting an attitude of selfcriticism that is essential to therapy. Yet at times this self-criticism borders on being destructive of the essential confidence in one's craft-for instance, the author discusses the point that physical restraint seems to be less often necessary as the therapist gains in experience, only to query whether the experienced therapist perhaps avoids taking on patients with such needs (p. 23). The book has thus much to offer to the experienced therapist who has faced such doubts in himself; it should also be useful for the supervisor, but it cannot be recommended for the beginner in child psychotherapy who is in need of clearer guide lines than are offered here.

IAN LOWIT

MENTAL RETARDATION: PRENATAL DIAGNOSIS AND Infant assessment By C. P. Douglas, and K. S. Holt. (Pp. 64; illustrated; £1·80.) Butterworths: London. 1972.

This small volume reports symposia held in 1970 and the spring of 1971 on the important topics named in 